\title{
THE PREVALENCE OF CIGARETTE SMOKING, E-CIGARETTE USE AND HEATED TOBACCO USE AMONG POLICE EMPLOYEES IN POLAND: A 2020 CROSS-SECTIONAL SURVEY
}

\section{MATEUSZ JANKOWSKI ${ }^{1}$, MARIUSZ GUJSKI ${ }^{2}$, JAROSŁAW PINKAS ${ }^{1}$, DAGMARA OPOCZYŃSKA-ŚWIEŻEWSKA ${ }^{2}$, EDYTA KRZYCH-FAŁTA ${ }^{2}$, ALEKSANDRA LUSAWA ${ }^{2}$, WALDEMAR WIERZBA ${ }^{3,4}$, and FILIP RACIBORSKI ${ }^{2}$}

${ }^{1}$ Centre of Postgraduate Medical Education, Warsaw, Poland

School of Public Health

${ }^{2}$ Medical University of Warsaw, Warsaw, Poland

Department of Prevention of Environmental Hazards and Allergology

${ }^{3}$ Central Clinical Hospital of the Ministry of the Interior and Administration in Warsaw, Warsaw, Poland

${ }^{4}$ University of Humanities and Economics in Łódź, Warsaw, Poland

UHE Satellite Campus in Warsaw

\begin{abstract}
Objectives: Uniformed services such as police employees are exposed to acute and chronic stressful events at work that may lead to tobacco use. This study aimed to assess the prevalence of cigarette smoking, e-cigarette use and heated tobacco use among police employees in Poland, and to investigate personal characteristics associated with tobacco or e-cigarette use. Material and Methods: This cross-sectional study was carried out in June-July 2020 on a randomly selected sample of 8789 police employees from the Mazowieckie Province, Poland. Results: Completed questionnaires were obtained from 5082 police employees (79.2\% being police officers) with an overall response rate of 57.8\%. Smoking $\geq 100$ cigarettes or similar amounts of other tobacco products was declared by $54.6 \%$ of the respondents, with significant differences $(\mathrm{p}<0.001)$ between males $(56.8 \%)$ and females $(50.3 \%)$. Daily cigarette smoking was declared by $19.5 \%$ of the respondents, and $13.4 \%$ were occasional cigarette smokers. Daily e-cigarette use was declared by $3.1 \%$ of the respondents, and $3.2 \%$ were occasional e-cigarette users. Daily heated tobacco use was declared by $2.6 \%$ of the respondents, and $2.9 \%$ were occasional heated tobacco users. Higher odds of occasional cigarette smoking were observed among men compared to women $(\mathrm{OR}=1.254,95 \% \mathrm{CI}: 1.009-1.558)$, and among the participants aged 20-29 years (OR $=7.982,95 \%$ CI: 3.066-20.775) or 30-44 years $(\mathrm{OR}=3.730,95 \%$ CI: $1.44-9.599)$ vs. those aged $\geq 60$ years. Higher odds of occasional e-cigarette use were observed among the participants aged 20-29 years $(\mathrm{OR}=4.554,95 \%$ CI: $1.213-17.101)$ vs. those aged 60 years. Police employees with office-based work had lower odds of daily cigarette smoking vs. those with fieldwork (OR $=0.726,95 \% \mathrm{CI}$ : $0.55-0.946)$. Police officers had higher odds of daily heated tobacco use compared to civil workers (OR $=3.362,95 \% \mathrm{CI}$ : $1.325-8.534)$. Conclusions: The authors observed a marked proportion of police employees who declared occasional tobacco or e-cigarette use, which may indicate the common social smoking phenomenon in this occupational group. Int J Occup Med Environ Health. 2021;34(5):629-45
\end{abstract}

Key words:

tobacco, smoking, epidemiology, police, e-cigarettes, heated tobacco use

Received: December 1, 2020. Accepted: January 26, 2021.

Corresponding author: Mariusz Gujski, Medical University of Warsaw, Department of Prevention of Environmental Hazards and Allergology, Banacha 1a, 02-091 Warsaw, Poland (e-mail: mariusz.gujski@wum.edu.pl). 


\section{INTRODUCTION}

Tobacco use is a leading cause of preventable deaths [1,2]. According to the World Health Organization (WHO) estimates, every year $>8$ million tobacco-related deaths are noticed globally [3]. In 2018, out of all cancer cases in the WHO European region, 27\% were attributed to tobacco use [4]. Poland is a country with a heavy burden of tobacco-related diseases, where the annual burden of tobaccoattributable deaths is estimated at over $>70000$ deaths [2]. Overall, it is estimated that smoking costs the EU countries at least EUR 100 billion per year [5].

In the WHO European region, the average rate of tobacco use is $26 \%$, with significant gaps between men (34\%) and women $(19 \%)[4,5]$. According to the data from the Special Eurobarometer 458 survey carried out in 2017, the highest prevalence of tobacco use was observed in Greece (37\%) and the lowest in Sweden (7\%). The prevalence of tobacco use is especially high in the Central and Eastern European region. Out of the $28 \mathrm{EU}$ countries analyzed in Special Eurobarometer 458, Poland was in the sixth place in terms of the rate of tobacco use [5].

In recent years, new forms of nicotine-containing products such as electronic cigarettes (e-cigarettes) and heated tobacco products have been gaining popularity [6]. In 2017, the prevalence of daily e-cigarette use in the EU ranged from $4.7 \%$ in the United Kingdom to $0.2 \%$ in Bulgaria [7]. However, the prevalence of e-cigarette use is the highest among adolescents and young adults, and can reach up to 27\% among students aged 13-19 years [8]. In 2014, the first heated tobacco products were launched in Europe, and the number of countries where they are available is constantly growing [6].

Data on the prevalence of heated tobacco use in Europe are very limited; nevertheless, it is estimated that approximately $1 \%$ of adult Europeans are daily heated tobacco users [6]. The proportion of Europeans who smoke dropped from $32 \%$ in 2006 to $26 \%$ in 2017 [9]. Nevertheless, there are disparities in smoking prevalence according to the socioeconomic status [10,11]. Income, education, and occupation affect the risk of tobacco use. Blue-collar workers are at higher risk than white-collar workers when it comes to ever or current smoking [11]. Among Europeans who are occupationally active (employed or self-employed), the highest prevalence of tobacco use was observed among manual workers (38\%) and self-employed (34\%), and the lowest among managers $(23 \%)$ [5].

The workplace is a major source of secondhand smoke (SHS) exposure for adults that contributes to ill health and diseases. Smoking in the workplace generates operational costs and reduces productivity affecting the health of workers [12]. Making workplaces smoke-free protects non-smokers from SHS but also encourages smokers to quit or reduce consumption [13]. A smoke-free policy should address the needs of different social and occupational groups. To develop an effective smoke-free policy, smoking behaviors in the general population as well as in individual risk groups should be evaluated.

Uniformed services such as police employees are exposed to acute and chronic stressful events at work. Occupational stress among police employees may lead to tobacco use [14]. While the prevalence of tobacco use in the general population in Poland is well documented [15], there is a lack of epidemiological studies on tobacco use among police employees in Poland.

This study aimed to assess the prevalence of cigarette smoking, e-cigarette use and heated tobacco use among police employees in Poland, and to investigate personal characteristics associated with tobacco or e-cigarette use.

\section{MATERIAL AND METHODS \\ Participants}

This cross-sectional study was carried out in June-July 2020 on a randomly selected sample of 8789 police employees from the Mazowieckie Province, Poland. The computer-assisted web interview (CAWI) tech- 
nique was used. A random quota sample was selected from 17800 police employees (officers and civil workers) from the Mazowieckie Province, Poland. The structures of the police in the Mazowieckie Province include the Mazowieckie garrison and the Warsaw garrison (the capital city of Warsaw and the surrounding poviats), which employ the largest number of police workers, among all 16 provinces (administrative regions) in Poland. The group selection technique (including the probability of drawing proportional to the size of the group) and the stratified selection technique were applied to provide a random selection of a study sample. All employees of the randomly selected police units were invited to participate in the study. Participation in the study was voluntary and anonymous. The study protocol was reviewed and approved by the Ethical Review Board at the Medical University of Warsaw, Warsaw, Poland (consent number: KB/87/2020).

\section{Study questionnaire}

The research tool was an original questionnaire developed for the purpose of this study. The questionnaire included 30 questions related to risk factors for COVID-19 as well as methods of SARS-CoV-2 infection prevention. Due to the previous scientific data on tobacco and e-cigarettes $[16,17]$ as potential risk factors for a SARS-CoV-2 infection, the authors decided to include questions on tobacco and e-cigarette use in the questionnaire developed in their study. Questions also addressed personal characteristics, including gender (male or female), age (years), the place of residence, living conditions, taking care of children, the type of employment (officers or civil workers), the service type, the presence of the chronic condition, and a self-reported health status.

Ever smoking was defined according to the answers to the questions: "Have you ever smoked $\geq 100$ cigarettes (or a similar amount of other tobacco products, e.g., pipes, cigars, cigarillos) in your lifetime?" Current smoking was defined according to the answers to the questions: "In the last 6 months, did you smoke or use the following nicotine-containing products: 1) cigarettes; 2) electronic cigarettes (e-cigarettes); 3) heated tobacco products (e.g., IQOS or glo)?" with 3 possible answers: "yes, daily," "yes, occasionally," and "no". This study was carried out as part of a research project aimed at investigating the prevalence of SARS-CoV-2 infections among police employees. Due to the fact that smoking and vaping were considered risk factors for a SARS-CoV-2 infection, the authors used a 6-month time frame (in contrary to 30 days which is widely used) to evaluate the smoking/vaping status of the participants during the COVID-19 pandemic.

\section{Statistical analysis}

The data were analyzed using SPSS ver. 26 (IBM, Armonk, NY, USA). The distribution of categorical variables was shown by frequencies and proportions along with $95 \%$ confidence intervals (CIs). Statistical testing to compare categorical variables was completed using the independent samples $\chi^{2}$ test. Associations between personal characteristics (gender, age, place of residence, housing conditions, type of employment [officers vs. civil workers], service type, self-reported health status and presence of chronic condition) with respect to the use of nicotinecontaining products were conducted using multiple logistic regression models. A total of 6 multivariate logistic regression models were developed. The use of the following nicotine-containing products was analyzed:

- traditional cigarettes,

- e-cigarettes,

- heated tobacco products.

Two models were developed for each of the nicotine-containing products, using 2 variants:

- daily use vs. non-use,

- occasional use vs. non-use.

These variables were introduced to the model as a series of $0-1$ variables (dummy variables). 


\section{RESULTS}

\section{Characteristics of the study population}

Completed questionnaires were obtained from 5082 police employees (79.2\% being police officers) with an overall response rate of $57.8 \%$. Two-thirds of the respondents were males. Most of the respondents (59\%) were aged $30-44$ years and served in preventive service (43\%). Detailed characteristics of the study population is presented in Table 1.

\section{Ever tobacco use}

Ever cigarette smoking (or smoking a similar amount of other tobacco products) was declared by $54.6 \%$ (95\% CI: 53.3-56.0) of the respondents, with significant differences $(\mathrm{p}<0.001)$ between males $(56.8 \%, 95 \%$ CI: 55.1-58.5) and females $(50.3 \%, 95 \%$ CI: 47.9-52.7). The percentage of the participants who had ever smoked was the highest among those aged $\geq 60$ years $(69.5 \%, 95 \%$ CI: 61.6-76.6) and the lowest among the youngest participants aged 20-29 years (48.8\%, 95\% CI: 45.1-52.6) ( $\mathrm{p}<0.001$ ). The highest percentage of the respondents who had ever smoked was recorded among those living in cities with 20 000-100 000 inhabitants (59.1\%; 95\% CI: 55.9-62.3), and the lowest among inhabitants of rural areas $(49.6 \%, 95 \%$ CI: 46.9-52.3) ( $\mathrm{p}<0.001)$.

In addition, the percentage of the respondents who had ever smoked was lower among those who had $\geq 1$ chronic condition $(53.1 \%, 95 \%$ CI: 51.4-54.8), compared to the participants without a chronic condition $(57.5 \%, 95 \% \mathrm{CI}$ : $55.2-59.8, \mathrm{p}<0.01)$. The percentage of ever smokers observed among the participants who defined their health status as very good $(50.6 \%, 95 \%$ CI: 48.3-52.9) was significantly lower $(\mathrm{p}<0.001)$, compared to those who declared bad or very bad health status (68.4\%, 95\% CI: 46.1-85.6). There were no statistically significant differences in ever tobacco use depending on the housing conditions, the type of employment (officers vs. civil workers) and the service type $(\mathrm{p}>0.05)$.

\section{Current cigarette smoking}

Daily cigarette smoking was declared by $19.5 \%$ (95\% CI: 18.4-20.6) of the respondents while occasional cigarette smoking was declared by $13.4 \%$ (95\% CI: 12.5-14.4). The prevalence of daily cigarette smoking as well as occasional cigarette smoking was higher $(\mathrm{p}<0.01)$ among men than among women, respectively $19.7 \%$ (95\% CI: 18.4-21.1) vs. $19.0 \%$ (95\% CI: 17.2-20.9), and $14.4 \%$ (95\% CI: $13.2-15.6)$ vs. $11.5 \%$ (95\% CI: 10.0-13.1). The highest prevalence of daily cigarette smoking $(21.2 \%)$ was observed among those living in cities with 20 000-100 000 inhabitants $(\mathrm{p}=0.03)$ as well as those respondents who declared living alone $(24.7 \%, \mathrm{p}<0.05)$.

Moreover, the highest prevalence of occasional (16.7\%) or daily $(23.8 \%)$ cigarette smoking was observed among the respondents who occasionally had children at home $(p<0.001)$. The prevalence of occasional cigarette smoking was higher among police officers (14.4\%), compared to civil workers $(9.6 \%, \mathrm{p}<0.001)$. A higher prevalence of cigarette smoking was observed among those respondents who declared a moderate, bad or very bad health status compared to those who declared a good or very good health status $(p<0.001)$. There were no significant differences $(p>0.05)$ in the prevalence of cigarette smoking depending on the presence of $\geq 1$ chronic condition $(p=0.3)$. Details are presented in Figure 1.

\section{Current e-cigarette use}

Daily e-cigarette use was declared by $3.1 \%$ (95\% CI: 2.7-3.7) of the respondents while occasional e-cigarette use was declared by $3.2 \%$ (95\% CI: 2.7-3.7). The prevalence of daily e-cigarette use as well as occasional e-cigarette use was higher ( $\mathrm{p}<0.01$ ) among men than among women, respectively $3.5 \%$ (95\% CI: $2.9-4.1$ ) vs. $2.5 \%$ (95\% CI: $1.9-3.4$ ), and $3.6 \%$ (95\% CI: $3.0-4.3$ ) vs. $2.4 \%$ (95\% CI: 1.7-3.2). The highest prevalence of daily or occasional e-cigarette use was the highest among the youngest respondents aged $20-29$ years $(p<0.001)$. Moreover, 
Table 1. Characteristics of the study population - a randomly selected sample of police employees from the Mazowieckie Province, Poland, June-July 2020

\begin{tabular}{|c|c|c|}
\hline \multirow[t]{2}{*}{ Variable } & \multicolumn{2}{|c|}{$\begin{array}{c}\text { Participants } \\
(\mathrm{N}=5082)\end{array}$} \\
\hline & $\mathrm{n}$ & $\%$ \\
\hline \multicolumn{3}{|l|}{ Gender } \\
\hline male & 3382 & 66.5 \\
\hline female & 1700 & 33.5 \\
\hline \multicolumn{3}{|l|}{ Age } \\
\hline 20-29 years & 688 & 13.5 \\
\hline $30-44$ years & 2999 & 59.0 \\
\hline $45-59$ years & 1254 & 24.7 \\
\hline$\geq 60$ years & 141 & 2.8 \\
\hline \multicolumn{3}{|l|}{ Place of residence } \\
\hline rural & 1316 & 25.9 \\
\hline \multicolumn{3}{|l|}{ urban } \\
\hline$<20000$ inhabitants & 742 & 14.6 \\
\hline 20 000-100 000 inhabitants & 900 & 17.7 \\
\hline $100001-500000$ inhabitants & 633 & 12.5 \\
\hline$>500000$ inhabitants & 1491 & 29.3 \\
\hline \multicolumn{3}{|l|}{ Housing conditions } \\
\hline living alone & 389 & 7.7 \\
\hline living with $\geq 1$ person & 4693 & 92.3 \\
\hline \multicolumn{3}{|l|}{ Children at home } \\
\hline yes, everyday & 2903 & 57.1 \\
\hline yes, occasionally (alternating care) & 168 & 3.3 \\
\hline no & 2011 & 39.6 \\
\hline \multicolumn{3}{|l|}{ Type of employment } \\
\hline police officer & 4026 & 79.2 \\
\hline civil worker & 1056 & 20.8 \\
\hline \multicolumn{3}{|l|}{ Service type } \\
\hline management & 338 & 6.7 \\
\hline preventive service & 2188 & 43.0 \\
\hline criminal service & 1263 & 24.9 \\
\hline support service & 489 & 9.6 \\
\hline logistics and technical service & 196 & 3.8 \\
\hline administrative worker & 379 & 7.5 \\
\hline other & 229 & 4.5 \\
\hline
\end{tabular}


Table 1. Characteristics of the study population - a randomly selected sample of police employees from the Mazowieckie Province, Poland, June-July 2020 - cont.

\begin{tabular}{lcc}
\hline & Variable & \multicolumn{2}{c}{$\begin{array}{c}\text { Participants } \\
\text { (N= 5082) }\end{array}$} \\
\cline { 2 - 3 } & \multicolumn{2}{c}{$\%$} \\
\cline { 2 - 3 } Type of work & 1530 & 30.1 \\
$\quad$ only office-based & 2673 & 52.6 \\
both office-based and fieldwork & 879 & 17.3 \\
$\quad$ only fieldwork & & \\
Presence of chronic condition & 1774 & 34.9 \\
yes & 3308 & 65.1 \\
$\quad$ no & & \\
Self-reported health status & 1829 & 36.0 \\
$\quad$ very good & 2832 & 55.7 \\
good & 402 & 7.9 \\
fair & 19 & 0.4 \\
poor & & \\
\hline
\end{tabular}

the highest prevalence of daily or occasional e-cigarette use was observed among those respondents who lived in big cities with $>500000$ inhabitants $(\mathrm{p}<0.001)$. The lowest prevalence of daily e-cigarette use was observed among those respondents who lived with children on a daily basis $(\mathrm{p}<0.001)$.

The prevalence of daily e-cigarette use as well as occasional e-cigarette use was higher $(\mathrm{p}<0.01)$ among police officers than among civil workers, respectively $3.3 \%$ vs. $2.5 \%$, and $3.6 \%$ vs. $1.6 \%$. The prevalence of e-cigarette use also varied by type $(p<0.05)$. There were no significant differences $(p>0.05)$ in the prevalence of e-cigarette use depending on the housing conditions, the self-reported health status and the presence of $\geq 1$ chronic condition ( $p>0.05)$. Details are presented in Figure 2.

\section{Current heated tobacco use}

Daily heated tobacco use was declared by $2.6 \%$ (95\% CI: 2.2-3.1) of the respondents while occasional heated tobacco use was declared by $2.9 \%$ (95\% CI: 2.4-3.3). The high- est prevalence of daily or occasional heated tobacco use was recorded among the youngest respondents aged 2029 years $(p<0.001)$. Moreover, the highest prevalence of daily or occasional heated tobacco use was observed among those respondents who lived in big cities with $>500000$ inhabitants $(\mathrm{p}<0.001)$ as well as those who declared living alone $(p<0.01)$. The highest prevalence of heated tobacco use was observed among the respondents who worked in criminal service $(p<0.05)$. There were no significant differences $(p>0.05)$ in the prevalence of heated tobacco use depending on gender, housing conditions, the type of employment, the self-reported health status and the presence of $\geq 1$ chronic condition ( $p>0.05$ ). Details are presented in Figure 3.

\section{Patterns of tobacco and e-cigarette use}

Among daily cigarette smokers ( $\mathrm{N}=989), 3.5 \%$ (95\% CI: 2.5-4.8) declared daily use of e-cigarettes, and $8.1 \%$ (95\% CI: 6.5-9.9) of daily smokers used e-cigarettes occasionally. Among occasional cigarette smokers $(\mathrm{N}=681)$, 


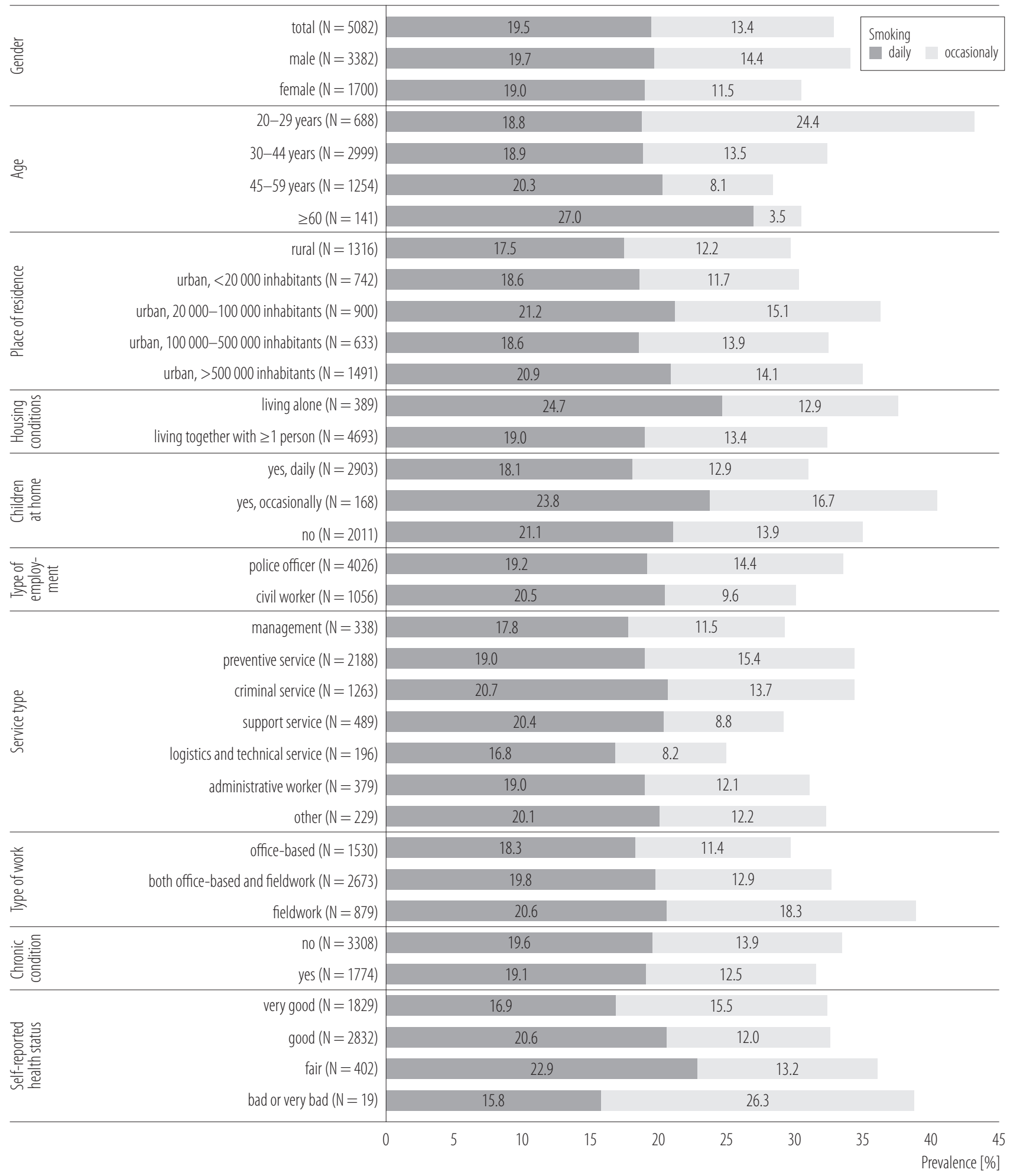

Figure 1. The prevalence of daily or occasional cigarette smoking by socioeconomic factors in a randomly selected sample of 5082 police employees from the Mazowieckie Province, Poland, June-July 2020 


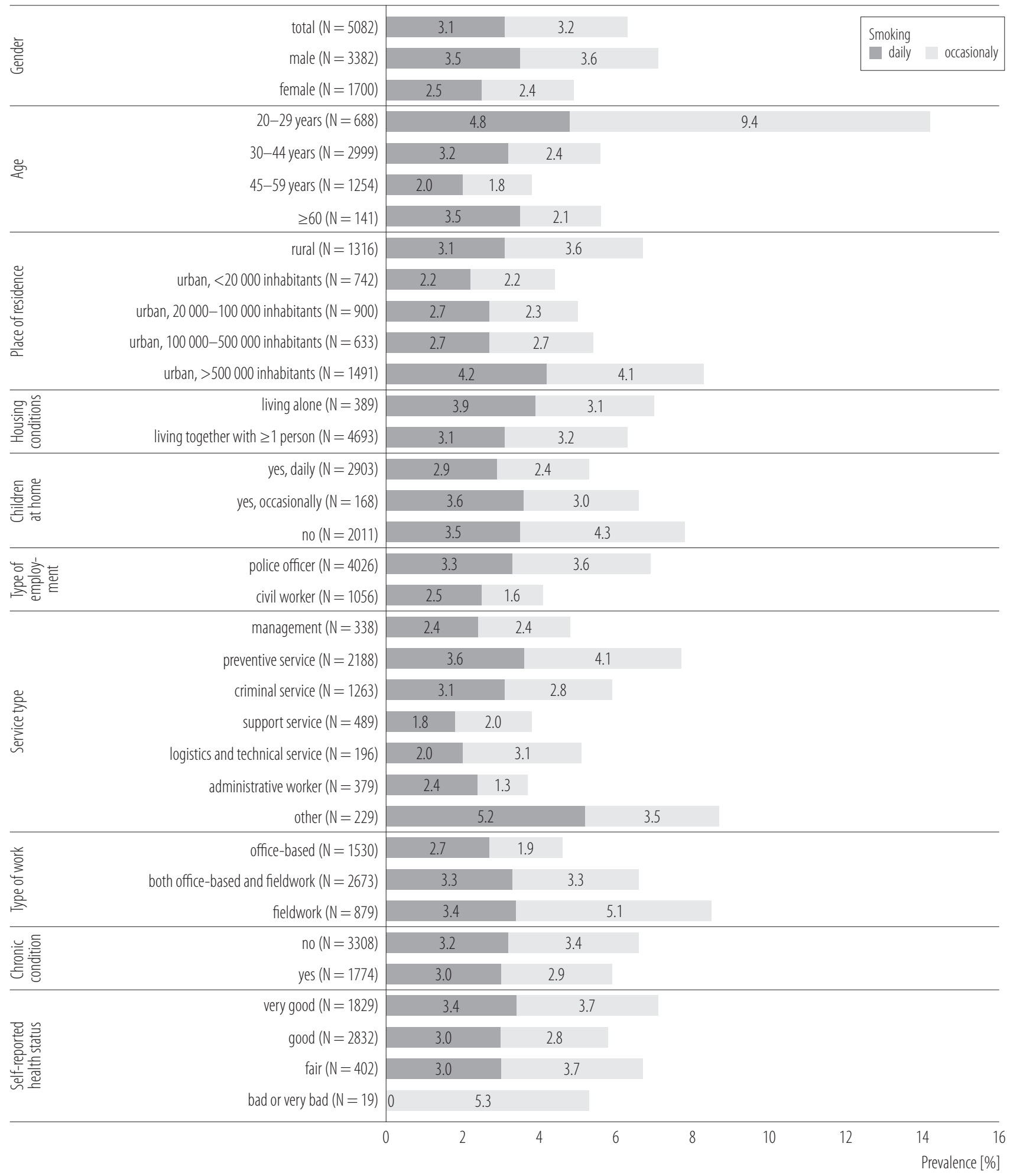

Figure 2. The prevalence of daily or occasional e-cigarette use by socioeconomic factors in a randomly selected sample of 5082 police employees from the Mazowieckie Province, Poland, June-July 2020 


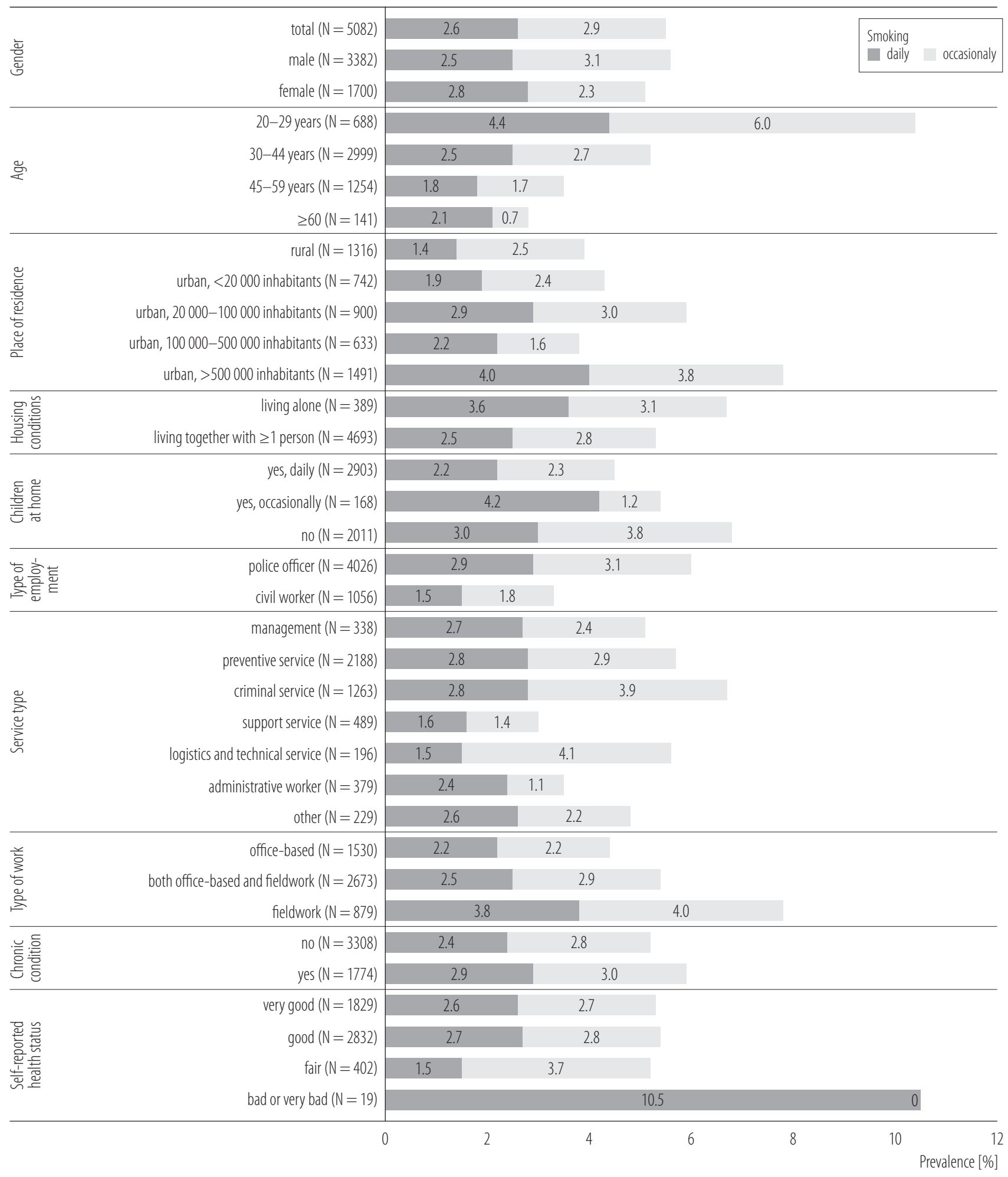

Figure 3. The prevalence of daily or occasional heated tobacco use by socioeconomic factors in a randomly selected sample of 5082 police employees from the Mazowieckie Province, Poland, June-July 2020 
7.8\% (95\% CI: 5.9-10.0) declared daily e-cigarette use, and $8.2 \%$ (95\% CI: 6.3-10.5) were occasional e-cigarette users.

Among daily cigarette smokers ( $\mathrm{N}=989), 4.3 \%$ (95\% CI: 3.2-5.8) declared daily use of heated tobacco, and 7.6\% (95\% CI: 6.1-9.4) of daily smokers used heated tobacco occasionally. Among occasional cigarette smokers $(\mathrm{N}=681), 7.5 \%$ (95\% CI: 5.7-9.6) declared daily heated tobacco use, and 7.5\% (95\% CI: 5.7-9.6) were occasional heated tobacco users.

Among daily e-cigarette users ( $\mathrm{N}=160), 11.3 \%$ (95\% CI: 7.1-16.8) declared daily use of heated tobacco, and $8.8 \%$ (95\% CI: 5.1-13.9) of daily e-cigarette users declared occasional use of heated tobacco. Among occasional e-cigarette users ( $\mathrm{N}=162), 6.2 \%$ (95\% CI: 3.2-10.7) declared daily heated tobacco use, and $23.5 \%$ (95\% CI: 17.4-30.4) were occasional heated tobacco users.

\section{Multiple logistic regression models}

The results of the multivariate regression analyses are presented in Table 2.

Model I assessed the impact of socioeconomic factors on daily cigarette smoking (vs. non-smokers) (Cox \& Snell R ${ }^{2}$ at 0.011 , Nagelkerke $R^{2}$ at 0.017 ). Higher odds of daily cigarette smoking were observed among the respondents living in towns with $20000-100000$ inhabitants (OR = 1.343, 95\% CI: 1.076-1.675) and in cities with >500 000 inhabitants (OR $=1.290,95 \%$ CI: $1.059-1.571)$ vs. those living in rural areas. Higher odds of daily cigarette smoking were observed among those respondents who defined their health status as good (OR $=1.333,95 \%$ CI: 1.129 $1.574)$ or fair (OR $=1.628,95 \%$ CI: $1.214-2.183)$ vs. those with a very good self-reported health status. Police employees with office-based work had lower odds of daily cigarette smoking vs. those with fieldwork $(\mathrm{OR}=0.726$, 95\% CI: 0.55-0.946).

Model II assessed the impact of socioeconomic factors on occasional cigarette smoking (vs. non-smokers) (Cox
\& Snell $\mathrm{R}^{2}$ at 0.035 , Nagelkerke $\mathrm{R}^{2}$ at 0.059 ). Higher odds of occasional cigarette smoking were observed among men compared to women $(\mathrm{OR}=1.254,95 \% \mathrm{CI}$ : 1.009-1.558), and among the participants aged 20-29 years $(\mathrm{OR}=7.982,95 \% \mathrm{CI}: 3.066-20.775)$ or $30-44$ years $(\mathrm{OR}=3.730,95 \%$ CI: $1.44-9.599)$ vs. those aged $\geq 60$ years. Higher odds of occasional cigarette smoking were observed among the respondents living in towns with $20000-100000$ inhabitants $(\mathrm{OR}=1.457$, 95\% CI: 1.126-1.886), in cities with 100 000-500 000 inhabitants $(\mathrm{OR}=1.400,95 \% \mathrm{CI}: 1.044-1.879)$ and in cities with $>500000$ inhabitants $(\mathrm{OR}=1.334,95 \% \mathrm{CI}$ : $1.057-1.685)$ vs. those living in rural areas. Higher odds of occasional cigarette smoking were observed among those respondents who defined their health status as good (OR=1.446, 95\% CI: 1.028-2.093) or fair $(\mathrm{OR}=3.098,95 \% \mathrm{CI}: 1.040-9.227)$ vs. those with very good self-reported health status.

Model III assessed the impact of socioeconomic factors on daily e-cigarette use (vs. non-users) (Cox \& Snell R ${ }^{2}$ at 0.007 , Nagelkerke $R^{2}$ at 0.029 ). None of the analyzed variables showed a statistically significant relationship.

Model IV assessed the impact of socioeconomic factors on occasional e-cigarette use (vs. non-users) (Cox \& Snell $\mathrm{R}^{2}$ at 0.022 , Nagelkerke $\mathrm{R}^{2}$ at 0.088 ). Higher odds of occasional e-cigarette use were observed among the participants aged 20-29 years $(\mathrm{OR}=4.554,95 \% \mathrm{CI}$ : $1.213-17.101)$ vs. those aged $\geq 60$ years, and those who defined their own health status as fair $(\mathrm{OR}=2.085$, $95 \%$ CI: $1.100-3.951)$ vs. those with a very good self-reported health status.

Model V assessed the impact of socioeconomic factors on daily heated tobacco use (vs. non-users) (Cox \& Snell $\mathrm{R}^{2}$ at 0.012 , Nagelkerke $\mathrm{R}^{2}$ at 0.054 ). Higher odds of daily heated tobacco use were observed among the respondents living in towns with $20000-100000$ inhabitants $(\mathrm{OR}=2.209,95 \%$ CI: 1.196-4.079), and in cities with $>500000$ inhabitants (OR $=3.104,95 \%$ CI: 1.801-5.349) 


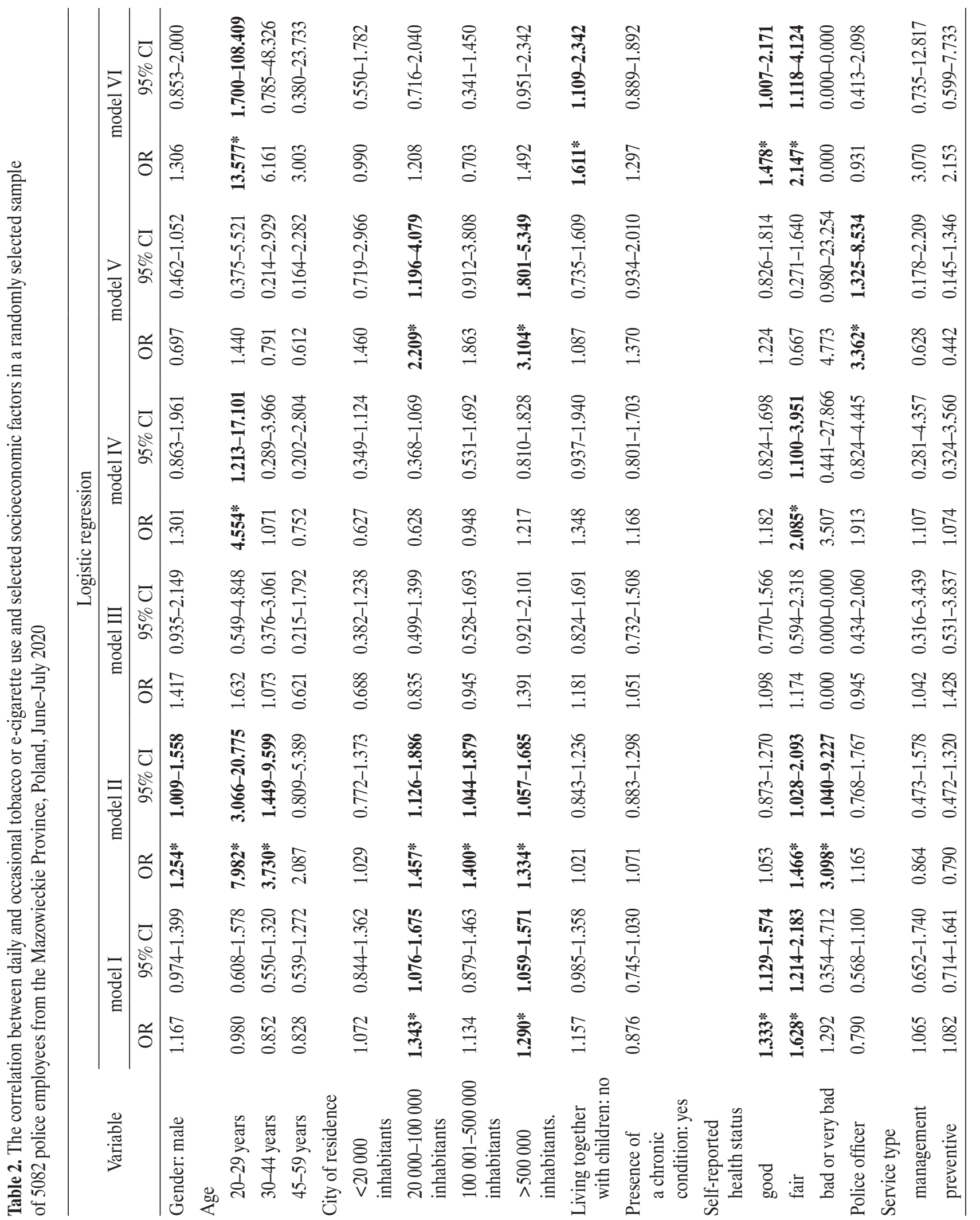




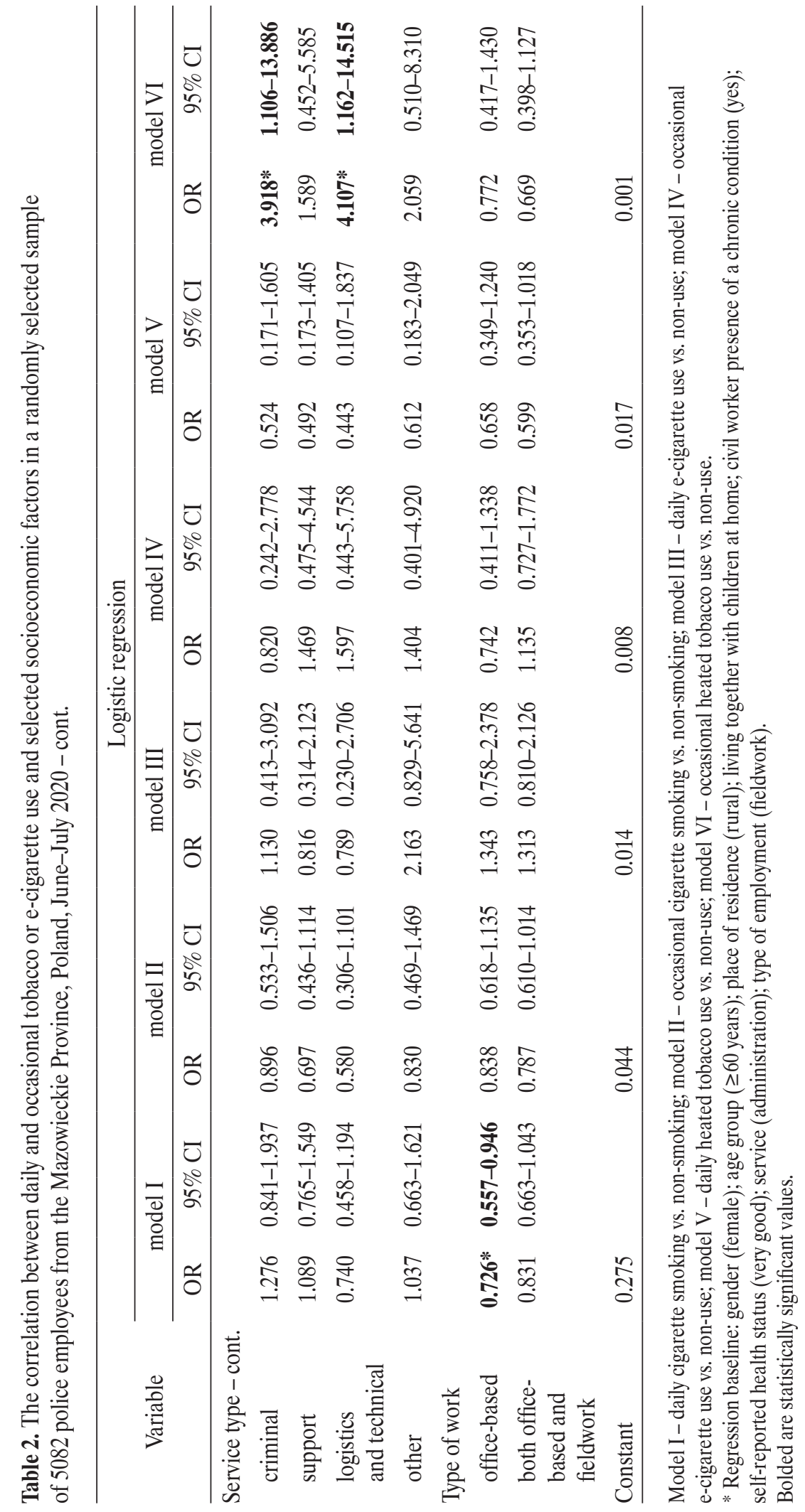


vs. those living in rural areas. Police officers had higher odds of daily heated tobacco use compared to civil workers $(\mathrm{OR}=3.362,95 \%$ CI: $1.325-8.534)$.

Model VI assessed the impact of socioeconomic factors on occasional heated tobacco use (vs. non-users) (Cox \& Snell $\mathrm{R}^{2}$ at 0.015 , Nagelkerke $\mathrm{R}^{2}$ at 0.064 ). Higher odds of occasional heated tobacco use were observed among the participants aged 20-29 years $(\mathrm{OR}=13.577,95 \% \mathrm{CI}$ : $1.700-108.409)$ vs. those aged $\geq 60$ years, and among the participants living without children $(\mathrm{OR}=1.611$, 95\% CI: 1.109-2.342) vs. those who had children at home. Higher odds of occasional heated tobacco use were observed among those respondents who defined their health status as good (OR $=1.478,95 \% \mathrm{CI}$ : $1.007-2.171)$ or fair $(\mathrm{OR}=2.147,95 \% \mathrm{CI}: 1.118-4.124)$ vs. those with a very good self-reported health status. Those participants who served in the criminal service $(\mathrm{OR}=3.918,95 \% \mathrm{CI}$ : 1.106-13.886) or the logistics and technical service (OR = 4.107, 95\% CI 1.162-14.515) had higher odds of occasional heated tobacco use compared to the participants engaged in other types of service.

\section{DISCUSSION}

To the best of the authors' knowledge, this is the most up-to-date epidemiological study on the prevalence of tobacco and e-cigarette use among police employees in Poland. These findings indicate that more than half of the police employees had ever smoked cigarettes and onefifth of them were daily smokers. Alternative forms of nicotine delivery, such as e-cigarettes and heated tobacco products, were less popular than traditional cigarettes; however, the proportion of occasional e-cigarette users or heated tobacco users was higher than the proportion of daily e-cigarette users or heated tobacco users. Gender, age, the place of residence and the self-reported health status significantly shaped smoking behaviors.

Monitoring tobacco use is the first point of the $6 \mathrm{MPO}$ WER tobacco control measures that may help the WHO
Member States reduce the demand for tobacco use [18]. Findings from 5 waves of a nationwide cross-sectional survey on tobacco use showed that the rate of tobacco use in Poland had decreased from $31 \%$ in 2011 to $21 \%$ in 2019 [15]. Despite the significant reduction in the number of smokers in Poland, there are still some social inequalities in terms of tobacco use [19]. Occupational stress and anxiety are associated with tobacco use $[14,20]$. Due to their working conditions, police employees can be classified to a higher risk group when it comes to tobacco use. According to Special Eurobarometer 458, in 2017, almost half (49\%) of EU citizens smoked $\geq 100$ tobacco products during their lifetime [5]. In Poland, 52\% of the general population had ever smoked [5]. In the present study, $54.6 \%$ of the participants had ever smoked, this figure being higher compared to those observed in the general Polish population. The authors observed some gender differences in ever smoking, which is in line with previously published data $[5,9,15]$. The prevalence of ever smokers increased with age. Preventing smoking initiation is one of the key tobacco control activities. The age differences in ever tobacco use may result from the decrease in tobacco consumption among Poles. The percentage of ever smokers was lower among the participants with a chronic condition. The presence of chronic conditions, especially respiratory illness, may discourage smoking initiation.

The proportion of daily cigarette smokers $(19.5 \%)$ was comparable to those observed in the general population (21\%) [15]. However, gender differences in daily smoking among police employees were lower, compared to the general population. In a national cross-sectional survey conducted in 2019 in Poland, daily smoking was declared by $18 \%$ of females and $24.4 \%$ of males [15]. In this study, the proportion of smokers was, respectively, 19\% among females and $19.7 \%$ among males. It can be hypothesized that this difference resulted from the fact that police employees are a relatively homogenous group, so their behaviors are comparable regardless of gender. The place 
of residence was significantly associated with the risk of daily tobacco use. In this study, the highest odds of daily tobacco use were observed among the respondents living in towns with $20000-100000$ inhabitants and in cities with $>500000$ inhabitants. This is in line with the observation from the 2019 nationwide cross-sectional survey, where the highest odds of daily tobacco use were observed among the respondents living in towns with 20 000-100 000 inhabitants [15].

In the past decade, an alternative form of nicotine delivery, such as e-cigarettes and heated tobacco products, were gaining popularity [6]. In this study, daily vaping (e-cigarette use) was declared by $3.1 \%$ of the participants, and $2.6 \%$ were daily heated tobacco users. The proportion of the participants using those novel nicotine-containing products was much higher, compared to the general population where the proportion of daily e-cigarette users or heated tobacco users was $1.4 \%$ and $0.4 \%$, respectively [15]. It can be hypothesized that, due to the advertising of these products as being less harmful to health (no scientific consensus on this matter), these products are more often chosen by police employees who, considering their working conditions, must maintain physical fitness and good health [6]. Moreover, the use of non-combustible nicotine-containing products by police officers may result from the fact that their use is difficult to detect in rooms or vehicles.

In this study, a substantial proportion of police employees were occasional cigarette smokers. The proportion of occasional cigarette smokers in this study was 10 times higher, compared to the general population $(13.4 \%$ vs. $1.3 \%$ ) [15]. Moreover, the proportion of occasional ecigarette users or heated tobacco users was comparable to the proportion of daily users. Such a high proportion of occasional tobacco or e-cigarette users among police employees may indicate a social smoking phenomenon [21,22]. Social smoking is defined as smoking primarily in social contexts [21]. Presumably, those police employees who are on duty within the same group for a long time may be vulnerable to smoke in this kind of a social situation. Moreover, smoking can be perceived as a habit which strengthens the sense of belonging to a particular group. The highest odds of occasional cigarette smoking were observed among the youngest age groups, which may suggest that those subjects smoke occasionally to maintain group acceptance among older colleagues [23]. In addition, some police employees may be inclined to smoke in stressful situations or while relaxing in a group of colleagues.

Smoking on a non-daily basis is associated with an increased risk of cancer, heart disease, and respiratory diseases [22]. It is estimated that occasional smokers, compared with never smokers, had a $72 \%$ higher all-cause mortality risk [24]. Such a high percentage of occasional smokers in this study points to an urgent need to provide anti-tobacco educational programs that would emphasize health risks arising from occasional smoking.

In this study, a marked proportion of police employees were dual users. A similar pattern of tobacco use is observed in other uniformed services, e.g., firefighters [25]. Presumably, the type of nicotine-containing products used depends on the time of the day and the social situation. Multiple nicotine-containing products use is a relatively new phenomenon. The health impact of poly-tobacco use is unknown. Social behaviors related to multiple nicotine products use as well as their impact on human health require further analysis.

Tobacco use in the workplace raises operational costs and reduces productivity [12]. Moreover, smoking in the workplace is associated with exposure to environmental tobacco smoke that is harmful to health [26]. In Poland, the number of companies introducing a smoking ban in the workplace is steadily increasing [27]. In 2009-2019, the proportion of Poles exposed to environmental tobacco smoke decreased from $25.4 \%$ to $6.7 \%$ [28]. However, further anti-tobacco activities are needed to promote smoke-free workplaces. Several practical implications emerge from this study. The proportion of occasional smokers among police em- 
ployees is several times higher than in the general population. Education on the health harm of occasional smoking should be included in the national tobacco control strategy. Moreover, this study points out that e-cigarettes and heated tobacco products are gaining popularity, especially among homogeneous occupational groups. Occupational smoking cessation interventions should account for noncigarette tobacco products. The promotion of a tobaccofree workplace should be a priority of tobacco control measures. Moreover, this study showed that multiple nicotine products use seems to be the next public health problem, and educational activities are needed to provide information about the health effects of dual or triple use of nicotine-containing products.

This study was carried out as a part of a research project on the prevalence of current and past SARS-CoV-2 infections among police employees in Poland [29]. Completing the questionnaire was obligatory to take part in laboratory tests for a SARS-CoV-2 infection because each respondent received an individual ID code for personal data after completing the questionnaire. It can be hypothesized that a relatively high response rate reported in this occupational setting may result from the study protocol and the organization of the individual stages of the study. Detailed sampling methods are presented in the previous paper [29].

This study has several limitations. Firstly, the smoking status was self-reported and was not verified biochemically [30]. Secondly, the authors focused on the prevalence of tobacco and e-cigarette use. Smoking behaviors such as the type of cigarettes smoked, the number of cigarettes per day, as well as the type of e-cigarette were not assessed. Thirdly, the occasional smokers/e-cigarette users were not inquired about the situations in which they smoked. Presumably, most of the occasional smokers were social smokers, but this observation should be addressed in further studies. Nonetheless, this is the first study on tobacco/e-cigarette use carried out in a random sample of police employees.

\section{CONCLUSIONS}

The prevalence of daily cigarette smoking among police employees was comparable to those observed in a general Polish population. However, the prevalence of daily e-cigarette use as well as heated tobacco use was higher compared to those observed in a general population. Smoking habits among police employees varied by gender, age, the health status, and the place of residence. The authors observed a marked proportion of police employees who declared occasional tobacco or e-cigarette use, and this observation requires further investigations. These observations can also be recognized as a step towards definite quitting and point to the urgent need to provide smoking cessation programs dedicated to uniformed services such as the police. A smoke-free policy addressed to police employees should include personalized and varied communication to officers and civil workers, and should educate them on the health risk of nondaily smoking.

\section{REFERENCES}

1. Oberg M, Jaakkola MS, Woodward A, Peruga A, PrüssUstün A. Worldwide burden of disease from exposure to second-hand smoke: A retrospective analysis of data from 192 countries. Lancet. 2011;377(9760):139-46, https://doi.org/10. 1016/S0140-6736(10)61388-8.

2. Eriksen M, Mackay J, Ross H. The Tobacco Atlas, 4th ed. Atlanta, GA: American Cancer Society; New York: World Lung Foundation, NY; 2012.

3. World Health Organization. WHO Global Report: Mortality Attributable to Tobacco. Geneva: World Health Organization; 2012.

4. World Health Organization [Internet]. WHO report on cancer: setting priorities, investing wisely and providing care for all. Geneva: The Organization; 2020 [cited 2020 Nov 9]. Available from: https://www.who.int/publications/i/item/whoreport-on-cancer-setting-priorities-investing-wisely-and-pro viding-care-for-all. 
5. European Commission [Internet]. Special Eurobarometer 458 - Attitudes of Europeans towards Tobacco and Electronic Cigarettes. Brussels: European Union, 2017 [cited 2020 Nov 9]. Available from: https://publications.europa. eu/en/publication-detail/-/publication/2f01a3d1-0af2-11e8966a-01aa75ed71a1/language-en.

6. Jankowski M, Brożek GM, Lawson J, Skoczyński S, Majek P, Zejda JE. New ideas, old problems? Heated tobacco products - a systematic review. Int J Occup Med Environ Health. 2019;32(5):595-634, https://doi.org/10.13075/ijomeh.1896. 01433.

7. Laverty AA, Filippidis FT, Vardavas CI. Patterns, trends and determinants of e-cigarette use in 28 European Union Member States 2014-2017. Prev Med. 2018;116:13-8, https:/doi. org/10.1016/j.ypmed.2018.08.028.

8. Kaleta D, Wojtysiak P, Polańska K. Use of electronic cigarettes among secondary and high school students from a socially disadvantaged rural area in Poland. BMC Public Health. 2016;15:703, https://doi.org/10.1186/s12889-016$3417-\mathrm{y}$.

9. Eurostat [Internet]. Smoking prevalence by sex. Brussels: European Union, 2020 [cited 2020 Nov 7]. Available from: https://ec.europa.eu/eurostat/databrowser/view/sdg_03_30/ default/table?lang=en.

10. Idris BI, Giskes K, Borrell C, Benach J, Costa G, Federico $\mathrm{G}$, et al. Higher smoking prevalence in urban compared to non-urban areas: time trends in six European countries. Health Place. 2007;13(3):702-12, https://doi.org/10.1016/j. healthplace.2006.11.001.

11. Ham DC, Przybeck T, Strickland JR, Luke DA, Bierut LJ, Evanoff BA. Occupation and workplace policies predict smoking behaviors: analysis of national data from the current population survey. J Occup Environ Med. 2011;53(11):133745, https://doi.org/10.1097/JOM.0b013e3182337778.

12. Ekpu VU, Brown AK. The Economic Impact of Smoking and of Reducing Smoking Prevalence: Review of Evidence. Tob Use Insights. 2015;8:1-35, https://doi.org/10.4137/TUI. S15628.
13. Fichtenberg CM, Glantz SA. Effect of smoke-free workplaces on smoking behaviour: systematic review. BMJ. 2002;325(7357):188, https://doi.org/10.1136/bmj.325.7357. 188.

14. Maran DA, Varetto A, Zedda M, Ieraci V. Occupational stress, anxiety and coping strategies in police officers. Occup Med (Lond). 2015;65(6):466-73, https://doi.org/10.1093/occmed/kqv060.

15. Pinkas J, Kaleta D, Zgliczyński WS, Lusawa A, Wrześniewska-Wal I, Wierzba W, et al. The Prevalence of Tobacco and E-Cigarette Use in Poland: A 2019 Nationwide Cross-Sectional Survey. Int J Environ Res Public Health. 2019;16(23):4820, https://doi.org/10.3390/ijerph16234820.

16. Vardavas CI, Nikitara K. COVID-19 and smoking: A systematic review of the evidence. Tob Induc Dis. 2020;18:20, https://doi.org/10.18332/tid/119324.

17. Gilpin DF, McGown KA, Gallagher K, Bengoechea J, Dumigan A, Einarsson G, et al. Electronic cigarette vapour increases virulence and inflammatory potential of respiratory pathogens. Respir Res. 2019;20(1):267, https://doi. org/10.1186/s12931-019-1206-8.

18. World Health Organization [Internet]. WHO Report on the Global Tobacco Epidemic, 2008: The MPOWER Package. Geneva: The Organization; 2020 [cited 2020 Nov 9]. Available from: https://www.who.int/tobacco/mpower/mpower_report_full_2008.pdf.

19. Milcarz K, Makowiec-Dąbrowska T, Bak-Romaniszyn L, Kaleta D. Smoking Patterns and Smoking Cessation Willingness - A Study among Beneficiaries of Government Welfare Assistance in Poland. Int J Environ Res Public Health. 2017; 14(2);131, https://doi.org/10.3390/ijerph14020131.

20. Kouvonen A, Kivimaki M, Virtanen M, Pentti J, Vahtera J. Work stress, smoking status, and smoking intensity: an observational study of 46190 employees. J Epidemiol Community Health. 2005;59(1);63-9, https://doi.org/10.1136/jech. 2004.019752.

21. Schane RE, Glantz SA, Ling PM. Social smoking implications for public health, clinical practice, and intervention 
research. Am J Prev Med. 2009;37(2):124-31, https://doi. org/10.1016/j.amepre.2009.03.020.

22. Schane RE, Ling PM, Glantz SA. Health effects of light and intermittent smoking: a review. Circulation. 2010;121(13): 1518-22, https://doi.org/10.1161/CIRCULATIONAHA.109. 904235 .

23. Song AV, Ling PM. Social smoking among young adults: investigation of intentions and attempts to quit. Am J Public Health. 2011;101(7):1291-6, https://doi.org/10.2105/AJPH. 2010.300012.

24. Inoue-Choi M, McNeel TS, Hartge P, Caporaso NE, Graubard BI, Freedman ND. Non-Daily Cigarette Smokers: Mortality Risks in the U.S. Am J Prev Med. 2019;56(1):27-37, https://doi.org/10.1016/j.amepre.2018.06.025.

25. Jitnarin N, Poston WSC, Haddock CK, Jahnke SA, Day RS. Tobacco use pattern among a national firefighter cohort. Nicotine Tob Res. 2015;17(1):66-73, https://doi.org/10.1093/ ntr/ntu131.

26. Brownson RC, Eriksen MP, Davis RM, Warner KE. Environmental tobacco smoke: health effects and policies to reduce exposure. Annu Rev Public Health. 1997;18:163-85, https://doi.org/10.1146/annurev.publhealth.18.1.163.
27. Korzeniowska E, Puchalski K. Solving the problem of smoking in the Polish enterprises during 2003-2015. Int J Occup Med Environ Health. 2018;31(3):261-80, https://doi. org/10.13075/ijomeh.1896.01164.

28. Jankowski M, Rees V, Zgliczyński WS, Kaleta D, Gujski M, Pinkas J. Self-reported secondhand smoke exposure following the adoption of a national smoke-free policy in Poland: analysis of serial, cross-sectional, representative surveys, 2009-2019. BMJ Open. 2020;10:e039918, https://doi. org/10.1136/bmjopen-2020-039918.

29. Gujski M, Jankowski M, Pinkas J, Wierzba W, Samel-Kowalik P, Zaczyński A, et al. Prevalence of Current and Past SARS-CoV-2 Infections among Police Employees in Poland, June-July 2020. J Clin Med. 2020;9(10):3245, https://doi. org/10.3390/jcm9103245.

30. Patrick DL, Cheadle A, Thompson DC, Diehr P, Koepsell T, Kinne S. The validity of self-reported smoking: A review and meta-analysis. Am J Public Health. 1994;84(7):1086-93, https://doi.org/10.2105/ajph.84.7.1086.

This work is available in Open Access model and licensed under a Creative Commons Attribution-NonCommercial 3.0 Poland License - http://creativecommons.org/ licenses/by-nc/3.0/pl/deed.en. 